\title{
Seasonal effects in the ionosphere-thermosphere response to the precipitation and field-aligned current variations in the cusp region
}

\author{
A. A. Namgaladze ${ }^{1,2}$, A. N. Namgaladze ${ }^{2}$, M. A. Volkov ${ }^{1,2}$ \\ ${ }_{1}^{1}$ Murmansk State Technical University, 13 Sportivnaya St., Murmansk, 183010, Russia (namgaladze@mstu.edu.ru) \\ ${ }^{2}$ Polar Geophysical Institute, 15 Halturina St., Murmansk, 183010, Russia (namgalad@polar.murmansk.su)
}

Received: 10 October 1997 / Revised: 9 June 1998 / Accepted: 11 June 1998

\begin{abstract}
The seasonal effects in the thermosphere and ionosphere responses to the precipitating electron flux and field-aligned current variations, of the order of an hour in duration, in the summer and winter cusp regions have been investigated using the global numerical model of the Earth's upper atmosphere. Two variants of the calculations have been performed both for the IMF $B_{y}<0$. In the first variant, the model input data for the summer and winter precipitating fluxes and field-aligned currents have been taken as geomagnetically symmetric and equal to those used earlier in the calculations for the equinoctial conditions. It has been found that both ionospheric and thermospheric disturbances are more intensive in the winter cusp region due to the lower conductivity of the winter polar cap ionosphere and correspondingly larger electric field variations leading to the larger Joule heating effects in the ion and neutral gas temperature, ion drag effects in the thermospheric winds and ion drift effects in the F2-region electron concentration. In the second variant, the calculations have been performed for the events of 28-29 January, 1992 when precipitations were weaker but the magnetospheric convection was stronger than in the first variant. Geomagnetically asymmetric input data for the summer and winter precipitating fluxes and field-aligned currents have been taken from the patterns derived by combining data obtained from the satellite, radar and ground magnetometer observations for these events. Calculated patterns of the ionospheric convection and thermospheric circulation have been compared with observations and it has been established that calculated patterns of the ionospheric convection for both winter and summer hemispheres are in a good agreement with the observations. Calculated patterns of the thermospheric circulation are in a good agreement with the average circulation for the Southern (summer) Hemisphere obtained from DE-2 data for IMF $B_{y}<0$ but for the Northern (winter) Hemisphere there is a disagreement at
\end{abstract}

Correspondence to: A. A. Namgaladze high latitudes in the afternoon sector of the cusp region. At the same time, the model results for this sector agree with other DE-2 data and with the ground-based FPI data. All ionospheric and thermospheric disturbances in the second variant of the calculations are more intensive in the winter cusp region in comparison with the summer one and this seasonal difference is larger than in the first variant of the calculations, especially in the electron density and all temperature variations. The means that the seasonal effects in the cusp region are stronger in the thermospheric and ionospheric responses to the FAC variations than to the precipitation disturbances.

Key words. Ionosphere (ionosphere-atmosphere interactions; ionosphere-magnetosphere interactions; ionospheric disturbances).

\section{Introduction}

There have been many reported ground-based and satellite investigations of the thermospheric and ionospheric responses to the soft electron precipitation and field-aligned current variations in the cusp region (e.g., Shepherd, 1979; Kelly and Vickrey, 1984; Kofman and Wickwar, 1984; McCormac and Smith, 1984; Oliver et al., 1984; Robinson et al., 1984; Smith, 1984; Vennerstrom et al., 1984; Wickwar, 1984; Thayer et al., 1987; Sandholt et al., 1994; Wu et al., 1996). However, there have been no reported systematic observational pictures of the seasonal behaviour of the thermospheric and ionospheric disturbances in the cusp region, partly due to the suppressive influence of the solar emission on the ionization and heating processes in the summer polar upper atmosphere.

Thermospheric and ionospheric responses to the precipitation and field-aligned current variations in the 
cusp have been investigated for the equinoctial conditions of 22 March, 1987 (low solar activity) by Namgaladze et al. (1996b) using the global numerical model of the Earth's upper atmosphere (Namgaladze et al., 1988, 1996a). This three-dimensional time-dependent model describes the ionosphere, thermosphere and protonosphere of the Earth as a single system and includes the calculations of the electric fields both of magnetospheric and thermospheric (dynamo) origin. A new version of this model, developed for studies of polar phenomena, employs variable latitudinal steps in the numerical integration scheme of the coupled equations, allowing us to enhance the latitudinal resolution of the model at those latitudes where this is necessary. The responses of the electron concentration, ion, electron and neutral temperature, wind velocity and electric field potential to the variations of a precipitating $0.23 \mathrm{keV}$ electron flux intensity with and without variations in the field-aligned current density in the cusp have been calculated by solving the corresponding continuity, momentum and heat balance equations.

Four variants of the calculations have been performed: (1) the cusp position is fixed and only the sudden precipitation of $0.23 \mathrm{keV}$ electrons takes place during $30 \mathrm{~min}$; (2) the cusp is moving from $78^{\circ}$ to $73^{\circ}$ and back and the precipitation flux is linearly increased and then decreased over $60 \mathrm{~min}$; (3) the same as in variant 2 but additional field-aligned currents corresponding to IMF $B_{y}<0$ are included, being linearly increased and then decreased during the hour; (4) the same as in variant 3 but the additional field-aligned currents maintain their maximum values after 00:30 UT.

The main prominent feature of the results of these calculations is that the thermospheric disturbances outside the cusp are generated mainly by the thermospheric heating due to the soft electron precipitation. They reveal appreciable magnitudes at significant distances from the cusp region being noticeably larger in case of the moving region of the precipitation. For example, the meridional wind velocity disturbance at $65^{\circ}$ geomagnetic latitude is of the same order as the background wind due to the solar heating but is oppositely directed. It has been concluded from these calculations that the most distinguishable disturbances outside of the cusp are those of the thermospheric wind.

The ionospheric disturbances have appreciable magnitudes at the geomagnetic latitudes $70^{\circ}-85^{\circ}$. The electron concentration and temperature disturbances are caused mainly by the ionization and heating processes due to precipitation. On the other hand the ion temperature disturbances are influenced strongly by Joule heating of the ion gas due to the field-aligned currents and associated electric field disturbances in the cusp. The latter strongly influence the meridional and, in particular, the zonal-wind disturbances via ion drag so these disturbances can reach values of about $200-$ $300 \mathrm{~m} / \mathrm{s}$ in the afternoon sector at $75^{\circ}-85^{\circ}$ geomagnetic latitude.

Now, in the present investigation we have studied mainly the seasonal effects in the thermospheric and ionospheric responses to the soft electron precipitation and field-aligned current variations, of the order of an hour in duration, in the summer and winter cusp regions simultaneously using the same model as in Namgaladze et al. (1996b). It should be expected that seasonal effects in the thermospheric and ionospheric disturbances may be rather significant due to at least two factors: (1) seasonal variations in the background state of the undisturbed thermosphere and ionosphere, i.e., of the neutral, ion and electron densities and temperatures and electric conductivities (Fuller-Rowell et al., 1988; Sojka and Schunk, 1989; Kirkwood, 1996); and (2) seasonal variations of the "input" parameters such as the precipitating particle fluxes and field-aligned current densities (Iijima and Potemra, 1976; Bythrow et al., 1982; Fujii and Iijima, 1987; Newell and Meng, 1988; LU et al., 1994, 1995). Correspondingly, two variants of the calculations have been performed both for the IMF $B_{y}<0$.

In the first variant, the model input data for the summer and winter precipitating fluxes and field-aligned currents have been taken as geomagnetically symmetric (i.e., symmetric relatively to the geomagnetic equator) and equal to those used earlier in our calculations for the equinoctial conditions (Namgaladze et al., 1996b) to investigate only the effects related with the background state of the ionosphere and thermosphere.

In the second variant, the calculations have been performed for the events of 28-29 January, 1992. Geomagnetically asymmetric input data for the summer and winter precipitating fluxes and field-aligned currents have been taken from the patterns derived by $\mathrm{Lu}$ et al. (1995) by combining data obtained from the satellite, radar and ground magnetometer observations for these events when precipitations were weaker but the magnetospheric convection was stronger than in the first variant. The results of the model calculations will be compared with those obtained in the first variant and with the observations and the possible physical causes of the predicted seasonal ionospheric and thermospheric effects in the cusp regions will be discussed.

Thus, the first variant of the calculations takes into account only the seasonal effects due to the seasonal variations in the background state of the undisturbed thermosphere (higher neutral temperature and density in summer) and ionosphere (higher electron concentration and conductivity in summer) which influence very strongly the ionization and electron, ion and neutral heating rates as well as the ion-neutral momentum exchange. It is very difficult, if at all possible, to understand and predict these seasonal effects only on the qualitative assessment basis, without any numerical model calculations because some processes influence the ionospheric and thermospheric parameters in the opposite way. For example, the soft electron precipitation increases the electron concentration in the F2-region whereas the enhanced temperature due to the enhanced Joule heating increases the ion loss rate and correspondingly decreases the electron concentration, both effects depend strongly on the background neutral gas temperature and density, etc. The merit of the numerical calculation is that it permits us to take into account 
many coupled physical processes in the ionosphere and thermosphere simultaneously.

The second variant of the calculations is more realistic because it considers not only the background seasonal variation of the ionospheric and thermospheric parameters but also includes the seasonal effects in the magnetospheric input parameters such as geometry and FAC intensity in accordance with data of LU et al. (1995). As has been shown, these seasonal effects in the input parameters do not influence noticeably the ionospheric and thermospheric responses to the precipitation and FAC variations in the cusp region. The effects of the background state are much more important as well as the relation between the precipitation and FAC intensity.

\section{The model}

The global numerical model of the Earth's upper atmosphere used in the presented calculations is threedimensional and time-dependent. It covers the height range from $80 \mathrm{~km}$ up to a geocentric distance of 15 Earth radii and takes into account the offset between the geomagnetic and geographic axes of the Earth. This model has been constructed at the Kaliningrad Observatory of IZMIRAN (Namgaladze et al., 1988, 1990, 1991, 1994) and modified for the polar ionosphere studies at the Polar Geophysical Institute in Murmansk (Namgaladze et al., 1996a). The model describes the thermosphere, ionosphere and protonosphere of the Earth as a single system by means of numerical integration of the corresponding time-dependent threedimensional continuity, momentum and heat balance equations for neutral, ion and electron gases as well as the equation for the electric field potential. The main difference between this global model and many others (e.g. Fuller-Rowell et al., 1988; Roble et al., 1988b; Schunk, 1988; Sojka 1989; Richmond et al., 1992; Roble and Ridley, 1994) is that not only winds, gas densities and temperatures of the thermosphere and ionosphere, but electric fields both of thermospheric dynamo and magnetospheric origin and protonospheric parameters are calculated as well.

The model consists of three main blocks: thermospheric, ionospheric-protonospheric and electric field computation blocks using different coordinate systems and different spatial grids of numerical integration. The exchange of information between these blocks is carried out at every time step of the numerical integration of the modelling equations.

In these blocks the corresponding well-known hydrodynamical continuity, momentum and heat balance equations for the neutral, electron and ion gases as well as the equation for the electric field potential are all solved numerically by the use of the finite difference methods to obtain the time and spatial variations of the following parameters: the total mass density $\rho$, concentrations of the main thermospheric gas constituents $n(\mathrm{O}), n\left(\mathrm{O}_{2}\right), n\left(\mathrm{~N}_{2}\right)$, the total concentration of the molecular ions $n\left(\mathrm{XY}^{+}\right)=n\left(\mathrm{O}_{2}{ }^{+}\right)+n\left(\mathrm{NO}^{+}\right)+n\left(\mathrm{~N}_{2}{ }^{+}\right)$, concentrations of the atomic ions $n\left(\mathrm{O}^{+}\right)$and $n\left(\mathrm{H}^{+}\right)$, temperatures of the neutral, ion and electron gases $T_{n}, T_{i}$ and $T_{e}$, thermospheric wind and ion velocity vectors $\mathbf{V}_{n}$ and $\mathbf{V}_{i}$, the electric field potential $\varphi$ and the electric field intensity vector $\mathbf{E}$. The detailed description of the model equations, initial and boundary conditions can be found in Namgaladze et al. (1988).

In the thermospheric block the modelling equations are solved in a spherical geomagnetic coordinate system. The same coordinate system is used to calculate the concentration, velocity and temperature of the molecular ions as well as the electron temperature at heights of $80-175 \mathrm{~km}$. The neutral atmosphere parameters calculated in the spherical geomagnetic coordinate system are interpolated to the nodes of the finite difference magnetic dipole coordinate grid to calculate the parameters of the ionospheric F2-region and the protonosphere. In turn, the necessary parameters of the ion and electron gases are put into the thermospheric block from the ionospheric-protonospheric block which uses the electric field from the electric field computation block. This latter block uses all necessary ionospheric and thermospheric parameters from the thermospheric and ionospheric-protonospheric blocks to calculate the conductivities and electric field potential.

In the high-latitude version of this model (Namgaladze et al., 1995, 1996a) we use the variable latitudinal steps of numerical integration. For the thermospheric and molecular ion parameters the latitudinal integration steps vary from $10^{\circ}$ at the geomagnetic equation to $2^{\circ}$ at the auroral zones. For the electric field, ionospheric F2region and protonospheric parameters they vary from $5^{\circ}$ at the geomagnetic equator to $2^{\circ}$ at the auroral zones. We have used this grid in the calculations presented. Namgaladze et al. (1996a) have shown that such a grid gives results which do not differ significantly from those obtained with a regular grid using the constant $2^{\circ}$ step in geomagnetic latitude. The time step of integration is $2 \mathrm{~min}$. Other steps of the numerical integration are $15^{\circ}$ in geomagnetic longitude and variable in altitude: $3 \mathrm{~km}$ near the lower boundary $(h=80 \mathrm{~km}), 5 \mathrm{~km}$ near $h=115 \mathrm{~km} .15 \mathrm{~km}$ near $h=220 \mathrm{~km}, 25 \mathrm{~km}$ near $h=330 \mathrm{~km}$ and $40 \mathrm{~km}$ near $h=500 \mathrm{~km}$, giving 30 levels in the altitude range from 80 to $520 \mathrm{~km}$ for the thermospheric parameters. The number of the nodes of the grid along $\mathbf{B}$ for the F2-region and protonospheric parameters varies from 9 on the lowest equatorial field line to maximum value 140 on the field line with $L=15$.

\section{Inputs}

\subsection{Variant 1: geomagnetically symmetric inputs, en- hanced precipitation, enhanced FACs in the cusp region, quiet zone-1 FACs}

In the first variant, we performed the model calculations for the solstice conditions of 22 June, 1987 (low solar activity). In these calculations, the same model input parameter variations as in variant 3 of the calculations made by Namgaladze et al. (1996b) for the equinoctial 
conditions of 22 March, 1987 have been used to investigate only the effects related with the background state of the ionosphere and thermosphere. Namely, the precipitating electron fluxes are taken at the upper boundary of the thermosphere $(h=520 \mathrm{~km})$ in a simple form:

$I=I_{m} \exp \left[-\left(\Phi-\Phi_{m}\right)^{2} /(\Delta \Phi)^{2}\left(\Lambda-\Lambda_{m}\right)^{2} /(\Delta \Lambda)^{2}\right]$,

where $\Phi, \Lambda$ are geomagnetic latitude and longitude, $\Delta \Phi, \Delta \Lambda$ characterize latitudinal and longitudinal dimensions of the precipitation area. The precipitating electron flux (a Maxwellian with characteristic energy of $0.23 \mathrm{keV}$ ) intensity in the cusp region $I_{m}$ and the geomagnetic latitude of the precipitation maximum $\Phi_{m}$ have been used as the variable inputs of the model, $\Delta \Phi=3.5^{\circ}, \Lambda_{m}$ corresponds to the local midday. $\Delta \Lambda=45^{\circ}$, i.e., the cusp region extends approximately from 9 to 15 MLT. The undisturbed value of $I_{m}$ has been chosen equal to $1.9 \times 10^{9} \mathrm{~cm}^{-2} \mathrm{~s}^{-1}$.

This flux was increased linearly with time during $30 \mathrm{~min}$ from 0000 UT to 0030 UT up to $19 \times 10^{9} \mathrm{~cm}^{-2} \mathrm{~s}^{-1}$. Simultaneously, the position of the intensity maximum moved from $78^{\circ}$ to $73^{\circ}$ geomagnetic latitude. During the next 30 min both maximum intensity and its position returned linearly to their initial levels. Such movements of the cusp have been observed, for example by Garbe et al. (1993) and Sandholt et al. (1994). Figure 1 (left top panel) shows the precipitating $0.23 \mathrm{keV}$ electron flux intensity at 0030 UT which is the time of the maximum of the disturbance; geomagnetic coordinates have been used here as in all other figures. In both Northern (summer) and Southern (winter) Hemispheres the precipitations are the same.

To investigate the effects of the disturbed fieldaligned current variations in the cusp for IMF $B_{y}<0$ we have used the following model input variations of the field-aligned currents based on the data by Reiff and Burch (1985), Taguchi et al. (1993), Yamauchi et al. (1993), and Ohtani et al. (1995). We have added the field-aligned current flowing into (out of) the ionosphere at the Northern (Southern) Hemisphere along the $80^{\circ}$ geomagnetic latitude at the 1130-1400 MLT sector and flowing out at the 1000-1130 MLT sector (right top panel in Fig. 1). These currents are closed by the
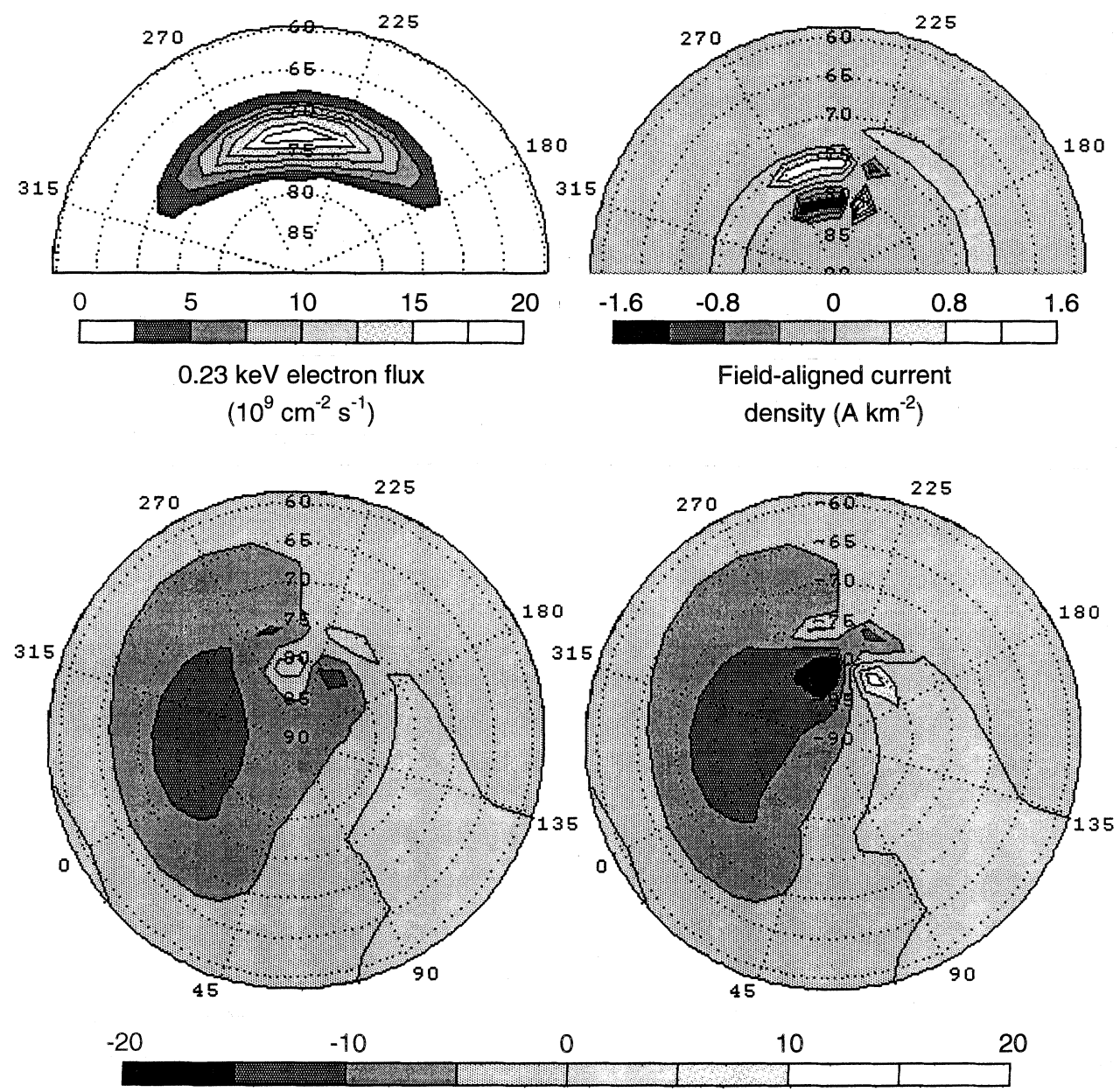

Electric potential (kV)

Fig. 1. Top panel: geomagnetic polar plots (latitudes $60^{\circ}-90^{\circ}$ ) of the input precipitation flux of $0.23 \mathrm{keV}$ electrons (left plot) and input fieldaligned current density (right plot) in the Northern Hemisphere at 0030 UT which is the time of maximum of the disturbance (variant 1 of the calculations). Bottom panel: calculated electric potential patterns in the Northern (summer, left plot) and Southern (winter, right plot) Hemispheres at 0030 UT. The Sun position is at the top 
additional zone 1 currents. The density of these additional field-aligned currents increases linearly from 0 to the maximum value during the first $30 \mathrm{~min}(0000-0030$ UT) and then recovers to 0 during the 30 min (0030 0100 UT). The maximum density of the field-aligned current flowing into the ionosphere at $80^{\circ}$ geomagnetic latitude is $1.6 \mathrm{~A} \mathrm{~km}^{-2}$ which is ten times larger than the quiet zone 1 field-aligned current density. The corresponding magnetic disturbance in the cusp region is estimated approximately as $600 \mathrm{nT}$. Such a disturbance was observed in the cusp region when $B_{y}$ component of IMF was equal -9 nT (Taguchi et al., 1993). It means that the modelled situation corresponds to the case when $B_{y}$ changes from 0 to $-9 \mathrm{nT}$ and back to 0 during an hour. The quiet region 1 and 2 FACs and $\mathrm{keV}$ electron precipitation fluxes are the same as in Namgaladze et al. (1996b).

The important question is that of the consistency between the precipitation and FACs. It was studied by many authors (McDiarmid et al., 1979; Bythrow et al., 1982; Friis-Christensen et al., 1985; Gussenhoven, 1988; Erlandson et al., 1988; Woch et al., 1993; Yamauchi et al., 1993; de La Beaujardiere et al., 1993; Xu and Kivelson, 1994; Lu et al., 1995). From their results we can conclude that the dayside soft electron precipitation and FAC region consists of the overlapping parts including the cusp proper copopulated with magnetosheath-like electrons, mantle FACs (traditional cusp FACs) shifted polewards from the cusp, near-noon part of region 1 currents, flowing partly along closed field lines and partly along open field lines, copopulated with cusp particles, and the other dayside region 1 FAC copopulated with low-latitude boundary layer (LLBL) type particles. We consider all this dayside precipitation and FAC region as "cusp region" meaning it is wider in latitude and longitude than the cusp proper and mantle FAC region. In our variant 1 of the simulation we have tried to reproduce all above mentioned features of this region. A physical motivation for our choice of the input parameters for this variant has been given in our previous paper (Namgaladze et al., 1996b) where this variant of the model input has been called "variant 3". The soft electron precipitation region extends in longitude approximately from 9 to 15 MLT and in magnetic latitude from approximately 70 to $80^{\circ}$ with the flux intensity maximum moving from 78 to $73^{\circ}$ and back in accordance with the observations by Garbe et al. (1993) and Sandholt et al. (1994). Such movement leads to more intense thermospheric wind disturbance (Namgaladze et al., 1996b) but does not influence noticeably the ionospheric electrodynamics because the soft electron precipitation influences mainly the F2-region electron concentration and does not influence significantly the Eregion and therefore the integrated ionospheric conductivity. The quiet region 1 currents flow between 74 and $78^{\circ}$ magnetic latitude, the open/closed field line boundary is at $76^{\circ}$, the additional "cusp FACs" flow between 78 and $82^{\circ}$ being closed by additional region 1 FACs. Of course, one can dispute any of these geomagnetic latitude values, but it should be noticed that the aim of this study is to investigate the large-scale $\left(\approx 5 \div 10^{\circ}\right.$ in latitude and $\approx 15^{\circ}$ in longitude) ionospheric and thermospheric effects of the dayside precipitation and FAC variation at the solstice which are rather insensitive to the small-scale (less than $2^{\circ}$ lat.) details of the input parameters.

\subsection{Variant 2: geomagnetically asymmetric inputs corresponding to the events of 28-29 January, 1992, quiet precipitation, enhanced FACs in the cusp and zone-1 regions}

The already described inputs are the same as in the calculations made by Namgaladze et al. (1996b) for the equinoctial conditions of 22 March, 1987 and that is the only reason to use them because it permits us to investigate the seasonal effects related only to the background state of the ionosphere and thermosphere. In reality, not only the background state of the ionosphere and thermosphere is different in the summer and winter but the precipitating fluxes and FACs may be different in the summer and winter hemispheres as well (Iijima and Potemra, 1976; Bythrow et al., 1982; Fujii and Iijima, 1987; Newell and Meng, 1988; Yamauchi and Araki, 1989; Lu et al., 1994, 1995). This is why we performed the second variant of the calculations where asymmetric input data for the summer and winter precipitating fluxes and field-aligned currents have been taken from the patterns derived by Lu et al. (1995) by combining data obtained from the satellite, radar and ground magnetometer observations for these events. Lu et al. (1995) used the assimilative mapping of ionospheric electrodynamics (AMIE) technique, derived by Richmond and Kamide (1988), to estimate global "snapshot" distributions of high-latitude convection and field-aligned current by combining data obtained nearly simultaneously both ground and from space.

Figures 2 and 3 show their ionospheric convection and field-aligned current patterns derived at 0155 UT on January 29, 1992, in the Northern Hemisphere (Fig. 2) and at 0011 UT on January 28, 1992, in the Southern Hemisphere (Fig. 3). By comparing these patterns with the corresponding spectrograms of precipitating particles, the following signatures have been identified by $\mathrm{Lu}$ et al. (1995). (1) For the cases studied, which all had an IMF with both $B_{y}$ and $B_{z}<0$ for more than $60 \mathrm{~min}$ prior to the time when the patterns were derived, the cusp precipitation was encountered by the DMSP satellites in the postnoon sector in the Northern Hemisphere and in the prenoon sector in the Southern Hemisphere. (2) The pair of field-aligned currents near local noon, i.e., the cusp/mantle currents, are coincident with the cusp or mantle particle precipitation. Thus these currents are generated on open field lines. As a distinction, the FACs on the dawnside and duskside, i.e., the region 1 currents, are usually associated with the plasma sheet precipitation and therefore they are generated mainly on closed field lines. (3) Topologically, the cusp/mantle currents appear as an expansion of the region 1 currents from the dawnside and duskside and 


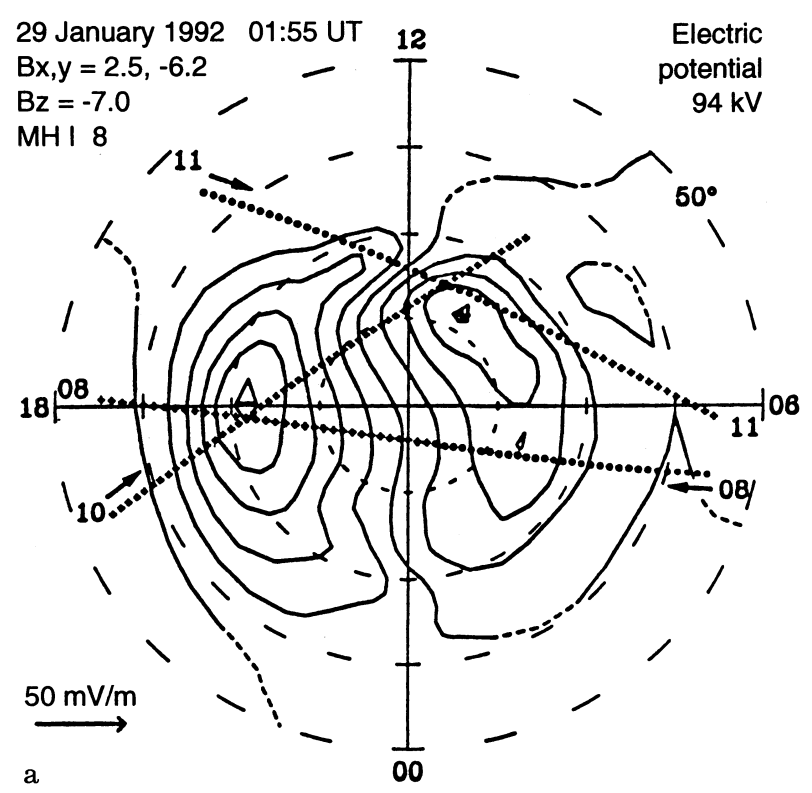

Fig. 2 a. The ionospheric convection pattern derived at 0155 UT on January 29, 1992, in the Northern Hemisphere. The pattern has a contour interval of $10 \mathrm{kV}$. The satellite trajectories which have been converted to apex coordinates are indicated as either dots (if the observations were made prior to 0155 UT) or plus signs (if they were made after 0155 UT). The solid arrows show the direction of the satellite motion. b Distribution of the field-aligned current density,

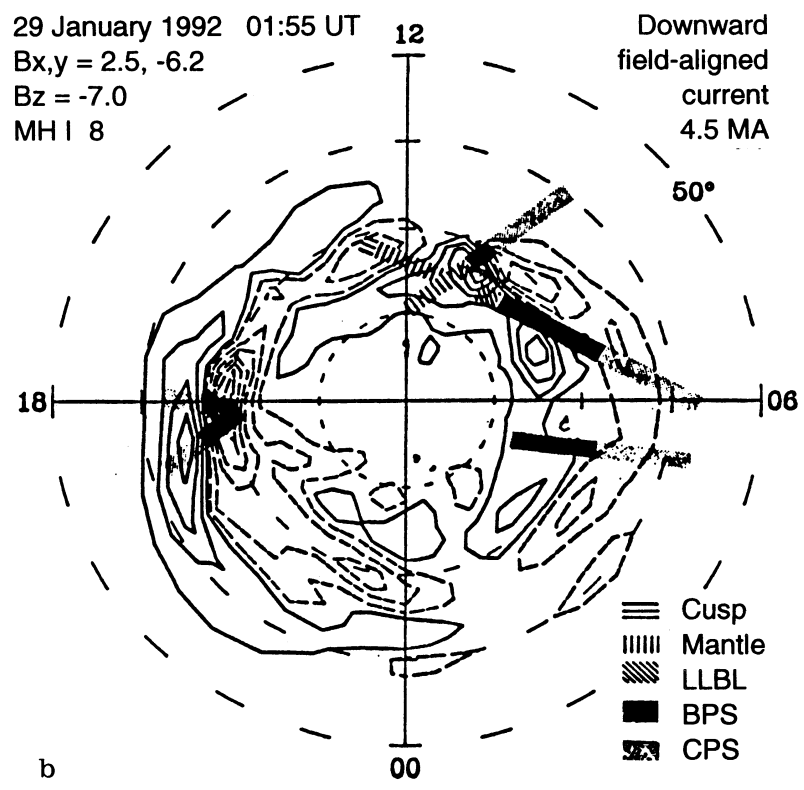

with solid lines representing the downward current and dashed lines the upward current. The contour interval is $0.3 \mu \mathrm{A} / \mathrm{m}^{2}$, starting $\pm 0.1 \mu$ $\mathrm{A} / \mathrm{m}^{2}$. The total downward current integrated over the area poleward of $50^{\circ}$ latitude is given at the upper right. The different magnetospheric plasma regimes are indicated by the different shadings, from Lu et al., (1995)
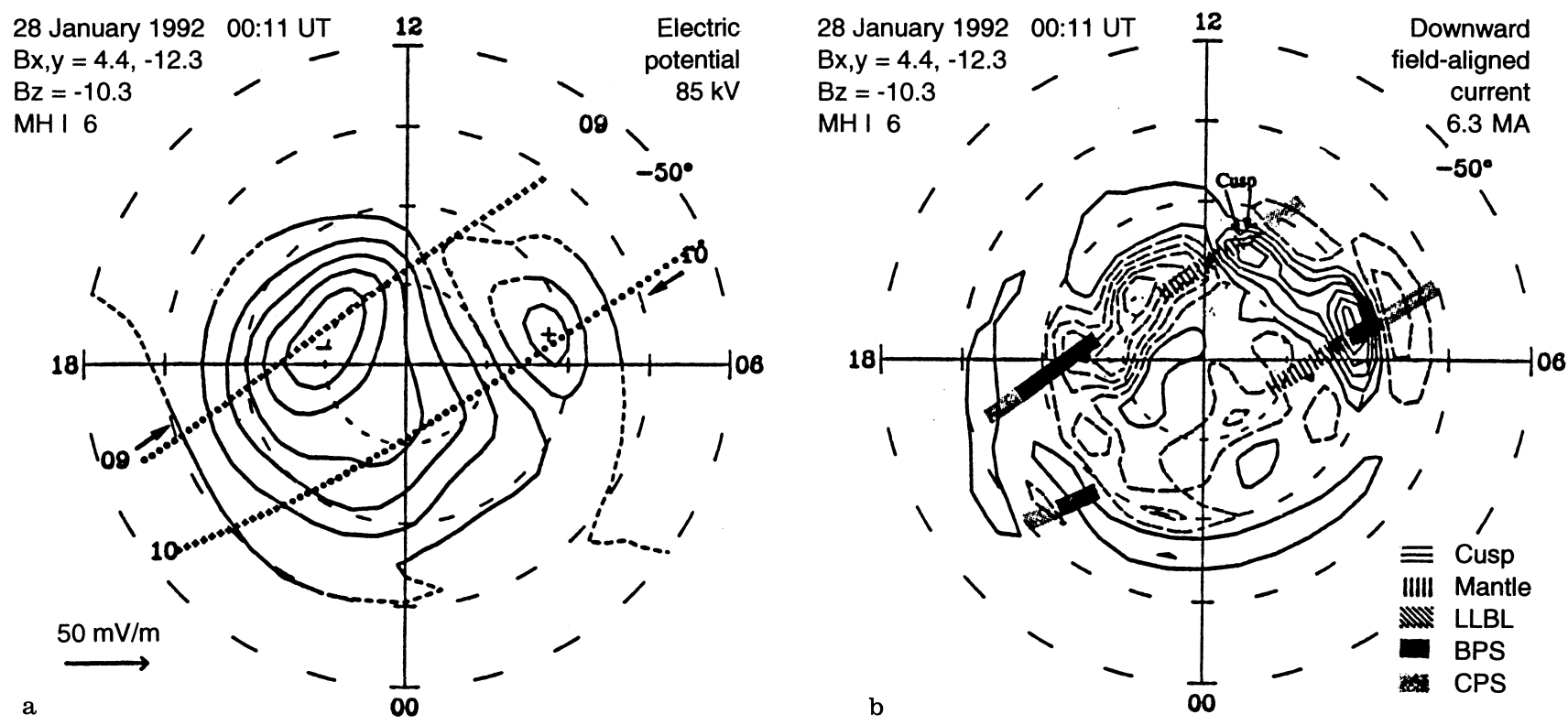

Fig. 3a, b. Patterns of the a ionospheric convection and b field-aligned current derived at 0011 UT on January 28, 1992, in the Southern Hemisphere. The contour interval for the field-aligned current is $0.4 \mu \mathrm{A} / \mathrm{m}^{2}$, starting $\pm 0.2 \mu \mathrm{A} / \mathrm{m}^{2}$, from Lu et al., (1995)

they overlap near local noon. When $B_{y}<0$ in the Northern Hemisphere the downward FAC is located poleward of the upward current: whereas in the Southern Hemisphere the upward current is located poleward of the downward current.

To reproduce these peculiarities of the FACs and precipitation, we have constructed more or less regular approximations of the field-aligned current density and soft electron (with average energy of $0.1 \mathrm{keV}$ ) precip- itating flux data shown in Fig. 4 (two upper panels) and used them as inputs for the second variant of the model calculations. These approximations take into account such differences between the hemispheres as the shift of the precipitation maximum to the postnoon sector in the Northern Hemisphere and to the prenoon sector in the Southern Hemisphere, more intensive FACs in the Southern Hemisphere (by a factor of about 1.5 in comparison with those in the Northern Hemisphere), 


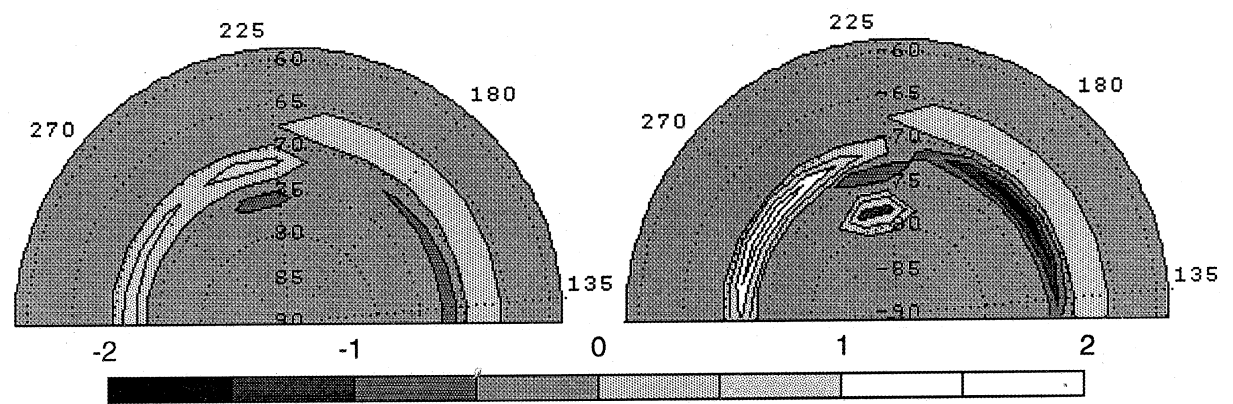

Field-aligned current density $\left(\mathrm{A} \mathrm{km}^{-2}\right)$
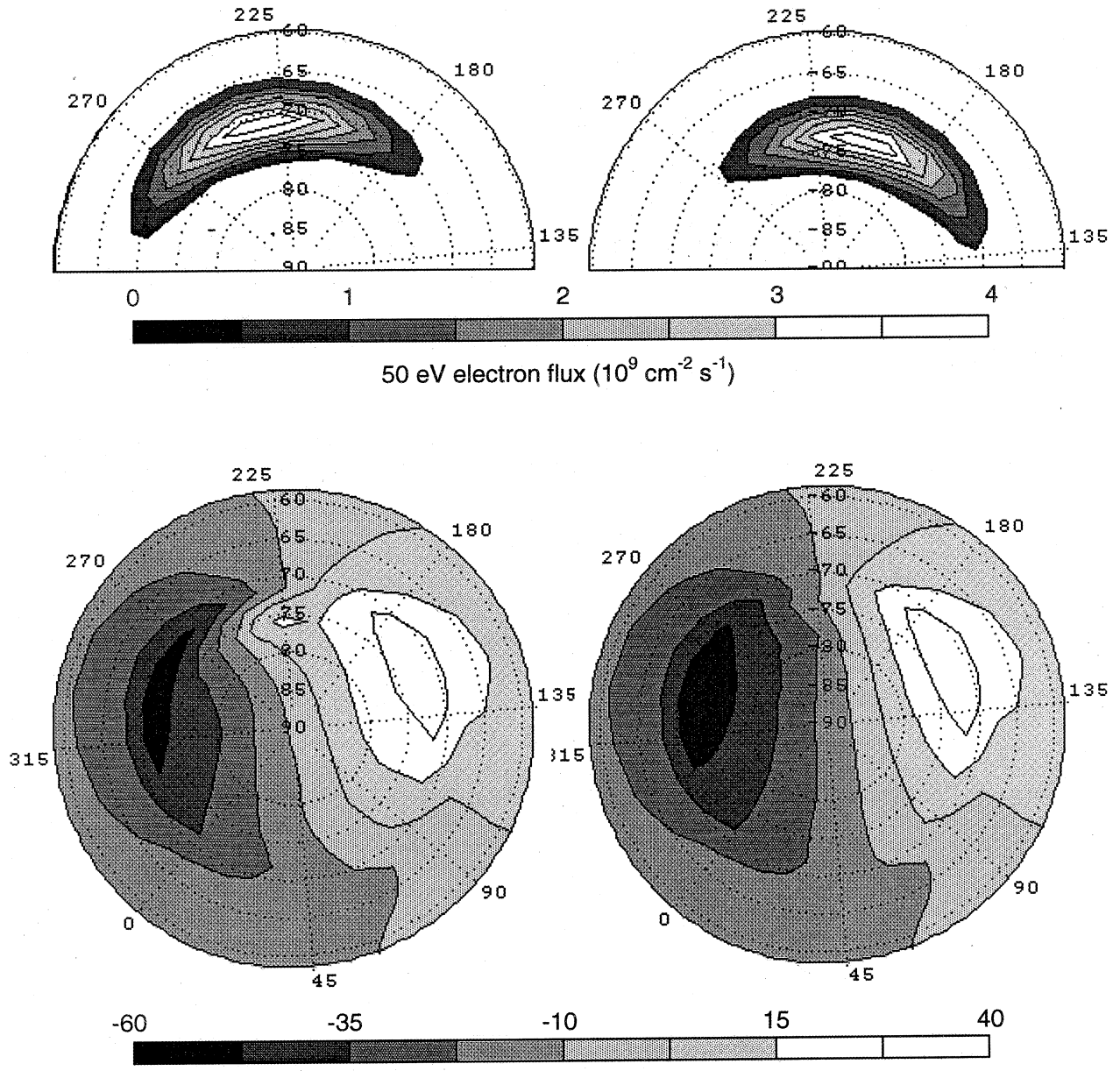

Electric potential (kV)

Fig. 4. Approximations of the field-aligned current density and soft electron (a Maxwellian with characteristic energy of $50 \mathrm{eV}$ ) precipitating flux data (two upper panels) used as inputs for the second variant of the model calculations. Bottom panel shows the calculated

opposite polarities of FACs in the cusp region and more poleward position of the cusp in the Southern Hemisphere in accordance with the data by Lu et al. (1995).

Thus the main differences between the inputs in variants 1 and 2 are the following: in variant 2 , the solar activity is high, the input precipitating electron fluxes and FACs are geomagnetically asymmetric and stable during two hours, the precipitating electron fluxes are weaker and FACs are stronger than in variant 1 . patterns of the ionospheric convection. The left plots correspond to the Northern (winter) Hemisphere, the right plots to the Southern (summer) Hemisphere. The Sun position is at the top

\section{Results of the calculations}

4.1 Variant 1 of the calculations (geomagnetically symmetric inputs, weak convection, enhanced precipitation)

Using the same geomagnetically symmetric inputs as in the calculations made by Namgaladze et al. (1996b) for the equinoctial conditions of 22 March, 1987, we performed the model calculations for the solstice 
conditions of 22 June, 1987. The electric field is calculated for a given FAC. The bottom panel in Fig. 1 shows the calculated electric field potential patterns at $0030 \mathrm{UT}$ in the summer (left plot) and winter (right plot) polar regions. The maximum electric field intensities are of about $30 \mathrm{mV} / \mathrm{m}$ in the summer cusp region and $70 \mathrm{mV} / \mathrm{m}$ in the winter cusp region in comparison with $30 \mathrm{mV} / \mathrm{m}$ obtained by Namgaladze et al. (1996b) for the equinoctial conditions. This difference is due to the different background conductivities in the summer and winter polar caps not connected with each other by the geomagnetic field lines because they are open there (the closed geomagnetic field lines equalize the electric potential; in the model used the boundary between the open and closed geomagnetic field lines is at $76^{\circ}$ geomagnetic latitude). It is the main cause of the seasonal effects in the ionospheric and thermospheric responses to the precipitation and field-aligned current variations in the summer and winter cusp regions. It is interesting that the potential pattern which consists of three convection cells at equinox (Namgaladze et al., 1996b), transforms to the four-cell pattern in solstice in both summer and winter hemispheres.

Figures 5 and 6 show the calculated ionospheric and thermospheric disturbances, i.e., the differences between disturbed and undisturbed values of the calculated electron concentration, electron, ion and neutral temperature, meridional (positive northwards) and zonal (positive eastwards) wind velocity at $300 \mathrm{~km}$ altitude in the summer (left plots) and winter (right plots) polar regions at the times of maximal disturbances (0030 UT for the ionospheric disturbances and 0040 UT for the thermospheric ones). A comparison of the results shown in the left and right columns in these figures demonstrates the

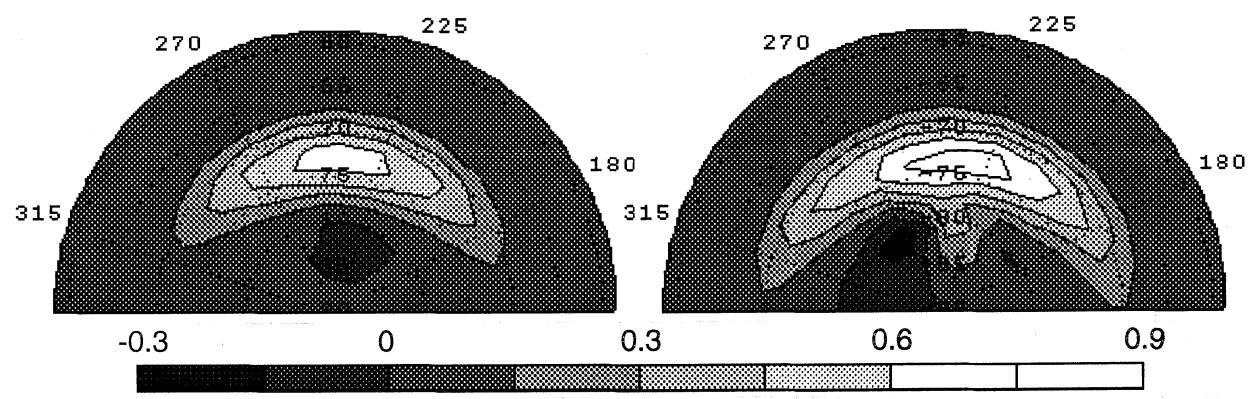

Electron concentration disturbance $(\Delta \mathrm{Lg} \mathrm{N})$

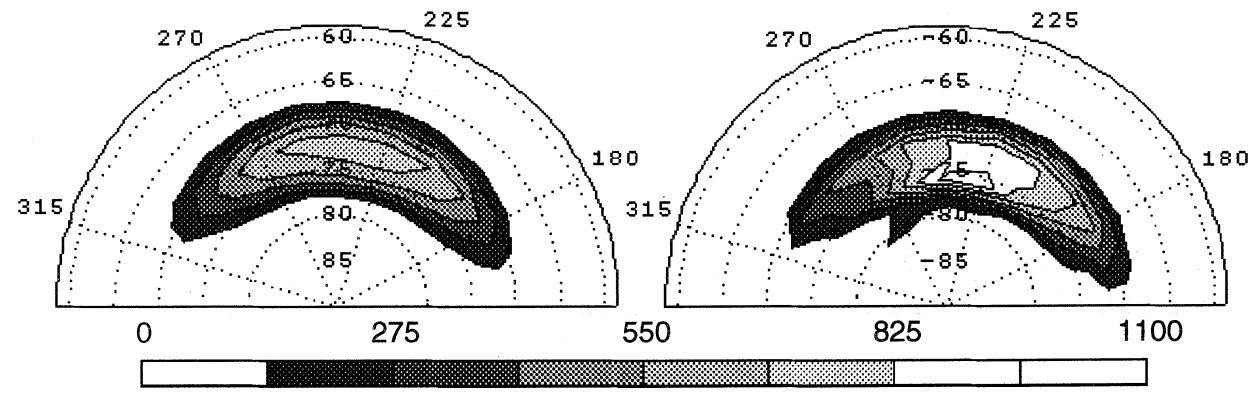

Electron temperature disturbance $(\mathrm{K})$

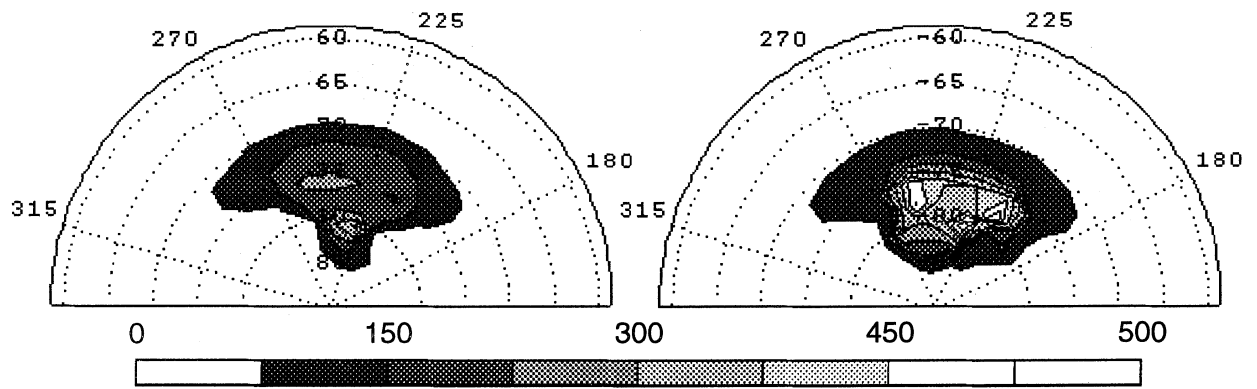

Ion temperature disturbance $(\mathrm{K})$

Fig. 5. Geomagnetic polar plots (latitudes $60^{\circ}-90^{\circ}$ ) of the calculated ionospheric disturbances, i.e., the differences between disturbed and undisturbed values of the calculated ionospheric parameters, at $h=300 \mathrm{~km}$ in the Northern (summer, left plot) and Southern (winter, right plot) Hemispheres at 0030 UT which is the time of maximum of the ionospheric disturbances. The Sun position is at the top 


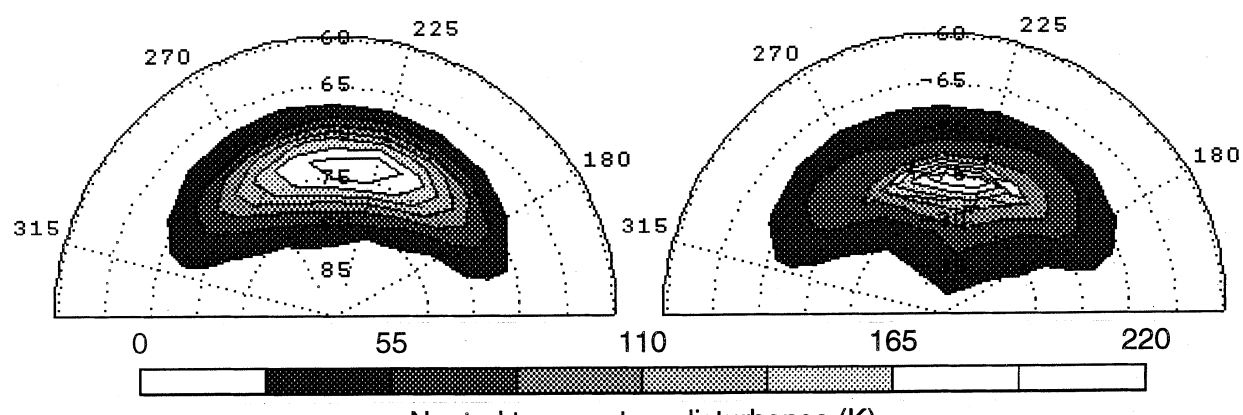

Neutral temperature disturbance $(\mathrm{K})$

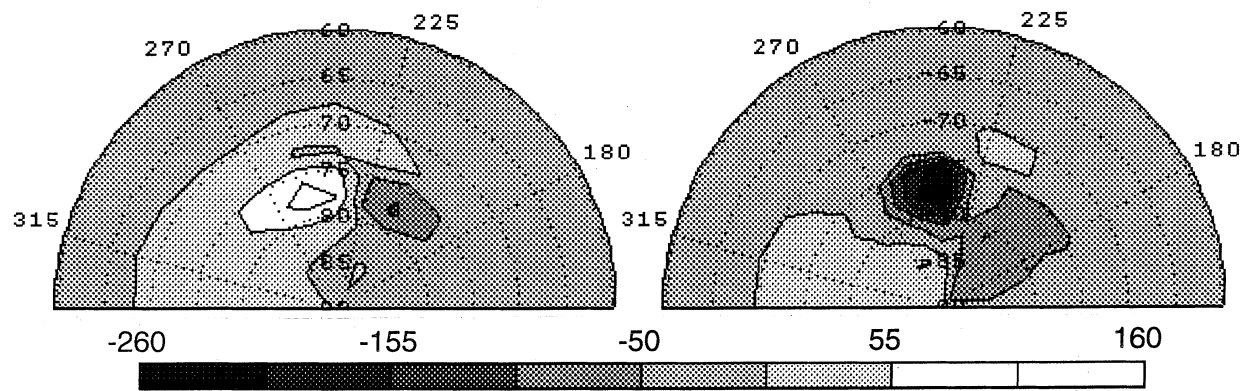

Eastward wind disturbance $\left(\mathrm{m} \mathrm{s}^{-1}\right)$

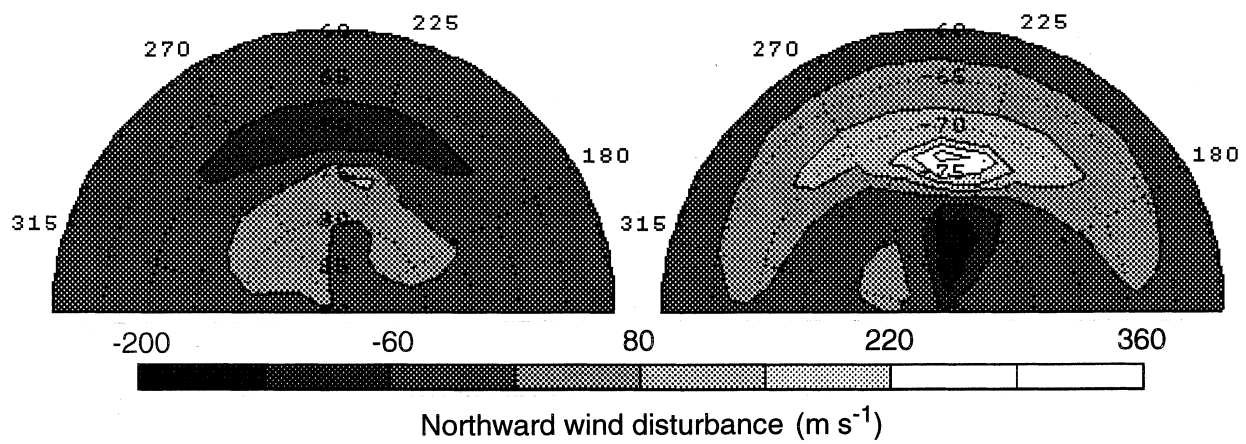

Fig. 6. Geomagnetic polar plots (latitudes $60^{\circ}-90^{\circ}$ ) of the calculated thermospheric disturbances, i.e., the differences between disturbed and undisturbed values of the calculated thermospheric parameters, at $h=300 \mathrm{~km}$ in the Northern (summer, left plot) and Southern

seasonal differences between the effects caused by the joint action of the precipitation and field-aligned current variations in the summer and winter cusp regions.

The electron concentration disturbances are caused mainly by the precipitating electron impact ionization although there is also an increase of the ion $\mathrm{O}^{+}$loss rate due to ion temperature and neutral composition disturbances, as well as ion transportation effects due to electromagnetic drifts. The maximum positive disturbance of $\lg N_{e}$ due to the precipitation in the cusp is 0.7 in the summer cusp region and 0.9 in the winter one in comparison with 0.8 in equinox. The ion drift effects are seen well in the winter cusp region at $80-85^{\circ}$ geomagnetic latitudes ("hole" and "tongue" in the right top plot in Fig. 5) but they are very weak in the summer cusp region.

The electron and ion temperature disturbances (middle and bottom panels in Fig. 5) both are larger in the (winter, right plot) Hemispheres at 0040 UT which is the time of maximum of the thermospheric disturbances. The Sun position is at the top

winter cusp region in comparison with summer one and this seasonal effect is more distinct in the ion temperature because of Joule heating of ion gas which depends on the electric field intensity. Max $\Delta T$ is $760 \mathrm{~K}$ in the summer and $1070 \mathrm{~K}$ in the winter cusp region in comparison with $950 \mathrm{~K}$ in equinox. Max $\Delta T_{i}$ is $390 \mathrm{~K}$ in the summer and $610 \mathrm{~K}$ in the winter cusp region in comparison with $600 \mathrm{~K}$ in equinox.

The neutral temperature disturbance is larger in the summer cusp region in absolute values (top panel in Fig. 6) but relative to the quiet background temperature (about $670 \mathrm{~K}$ in the winter cusp region and $1000 \mathrm{~K}$ in the summer one) it is noticeable larger in the winter cusp region by about $30 \%$ in comparison with $20 \%$ in the summer cusp region and in equinox.

Correspondingly, the neutral composition disturbances (not shown) are larger in the winter cusp region 
where the $\mathrm{O} / \mathrm{N}_{2}$ concentration ratio diminishes by about $45 \%$ at $75^{\circ}$ geomagnetic latitude in comparison with $15 \%$ in the summer cusp region and $25 \%$ in equinox.

The zonal thermospheric wind disturbances due to the ion drag are largest in the winter cusp region (Southern Hemisphere) where they reach values of about $260 \mathrm{~m} / \mathrm{s}$ being directed westwards in the 12-14 MLT sector in comparison with $140 \mathrm{~m} / \mathrm{s}$ eastward wind disturbances in this sector of the summer cusp region (middle panel in Fig. 6). In equinox, the maximum zonal wind disturbances were of about $300 \mathrm{~m} / \mathrm{s}$, eastward in the Northern Hemisphere and westward in the Southern Hemisphere.

The meridional wind disturbances are caused mainly by the pressure gradient forcing in the midday sector. They reach the largest values of about $320 \mathrm{~m} / \mathrm{s}$ in the winter cusp region being directed equatorwards in comparison with $120 \mathrm{~m} / \mathrm{s}$ in the summer cusp region (bottom panel in Fig. 6) and $180 \mathrm{~m} / \mathrm{s}$ in equinox.

So, all ionospheric and thermospheric disturbances caused by the precipitation and field-aligned current variations in the cusp are more intensive in the winter cusp region in comparison with the summer one.

As for the speed of the horizontal propagation of the disturbances, it is apparently higher at the high summer latitudes compared with the winter ones as seen in Fig. 7. This shows the time variations of the meridional wind velocity disturbance at $300 \mathrm{~km}$ height at latitudes 70,65 and $60^{\circ}$ in the summer (solid lines) and winter (dashed lines) hemisphere. Estimated at the $70-65^{\circ}$ latitude interval, the horizontal propagation speed is about $770 \mathrm{~m} / \mathrm{s}$ in the summer hemisphere and about $680 \mathrm{~m} / \mathrm{s}$ in the winter one. This difference is due evidently to the seasonal difference in the background temperature of the thermosphere and it depends on latitude, decreasing equatorwards.

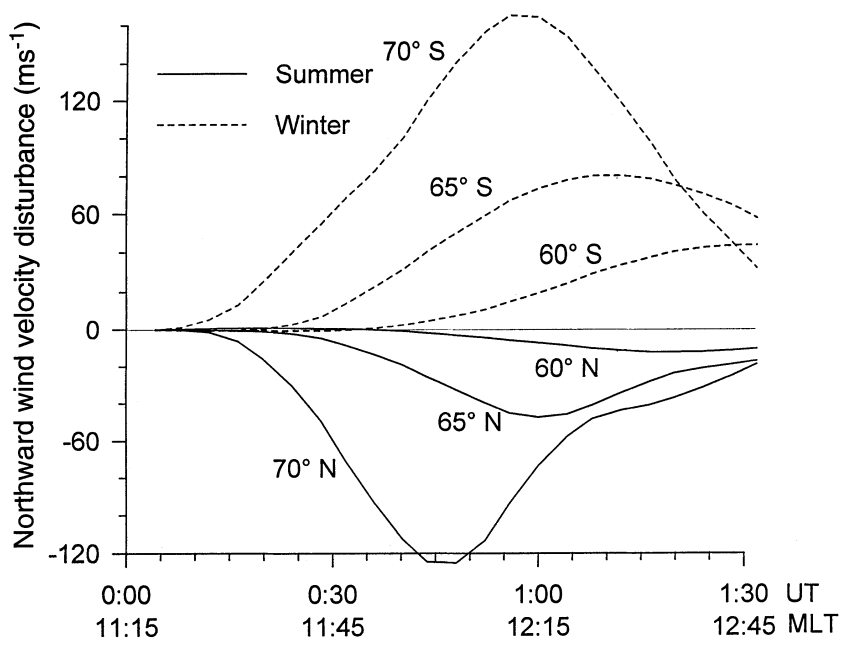

Fig. 7. The time variations of the meridional wind velocity disturbance (positive northward) at height $300 \mathrm{~km}$ at latitudes 70, 65 and $60^{\circ}$ in the summer (solid lins) and winter (dashed lines) hemisphere (variant 1 of the calculations)
4.2 Variant 2 of the calculations (geomagnetically asymmetric inputs, enhanced convection, quiet precipitation)

This variant of the calculations was performed in the following way. Starting from the "quiet" (i.e., undisturbed by the FACs in the cusp region) conditions at 0000 UT on 28 January, 1992, we inserted the "disturbed" input values for the FACs in the cusp region in accordance with the data shown in Fig. 4 and ran the model till 0200 UT. The cusp position and precipitation and FAC intensities were stable during this time period. Then we repeated the calculations from 0000 to 0200 UT without the FACs in the cusp region but with the same precipitating electron fluxes shown in Fig. 4 as in the previous case. The difference between the results of these calculations made with and without the FACs in the cusp region we call the "disturbance due to the FACs in the cusp region".

The bottom panel in Fig. 4 shows the calculated patterns of the electric field potential at 0200 UT for the Northern (winter; left plot) and Southern (summer; right plot) Hemispheres. A comparison of these patterns with those obtained by Lu et al. (1995) (Figs. 2 and 3) shows a good agreement between them. It is not so trivial that our model result is in good agreement with $\mathrm{Lu}$ et al.'s (1995) convection, because the «external» part is not absolutely the same, and in addition we used our own ionospheric conductivity calculated simultaneously with convection using precipitating electron fluxes. The agreement means that our approximation of Lu et al.'s (1995) FACs and our conductivity model permits us to obtain quantitatively a correct distribution of the electric potential both in summer and winter hemispheres. It is worth pointing our that the data of Lu et al. (1995) correspond to the different but adjacent days of 28 and 29 January, 1992 when both IMF $B_{y}$ and $B_{z}$ components were negative whereas our model calculations correspond to the single day of 28 January, 1992 with different FACs and precipitations in the Northern and Southern Hemispheres. Nevertheless, both observed and calculated patterns reveal the similar differences between the hemispheres: (1) the electric fields are more intensive in the winter cusp region whereas FACs are larger in the summer one and (2) the zonal component of the ion flow at the geomagnetic latitudes $>72^{\circ}$ is eastward in the winter cusp region and westward in the summer one.

These peculiarities of the ion flow are reflected very well in the calculated patterns of the horizontal thermospheric wind shown in Fig. 8. The top panel in this figure shows the calculated patterns of the horizontal thermospheric wind velocity at $300 \mathrm{~km}$ height for 28 January, 1992 in the Northern (winter; left plots) and Southern (summer, right plots) Hemispheres. The bottom panel in Fig. 8 shows the calculated patterns of the wind disturbance, i.e., the difference between the wind velocities calculated with and without taking into account the FACs in the cusp region. These patterns demonstrate an appearance of the eastward wind disturbances of about $200 \mathrm{~m} / \mathrm{s}$ in the afternoon cusp 
28.01.92 02:00 UT $h=300 \mathrm{~km}$

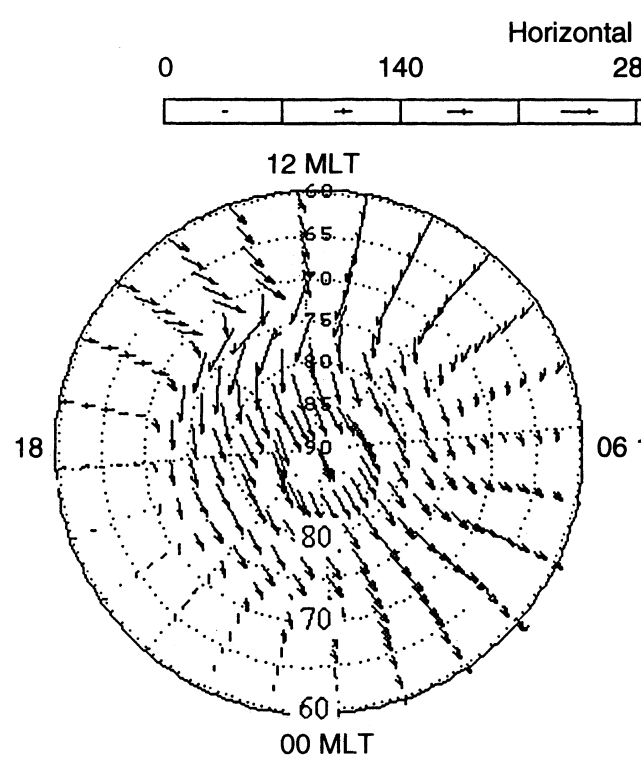

280
intal wind $\left(\mathrm{m} \mathrm{s}^{-1}\right)$

$420 \quad 560$

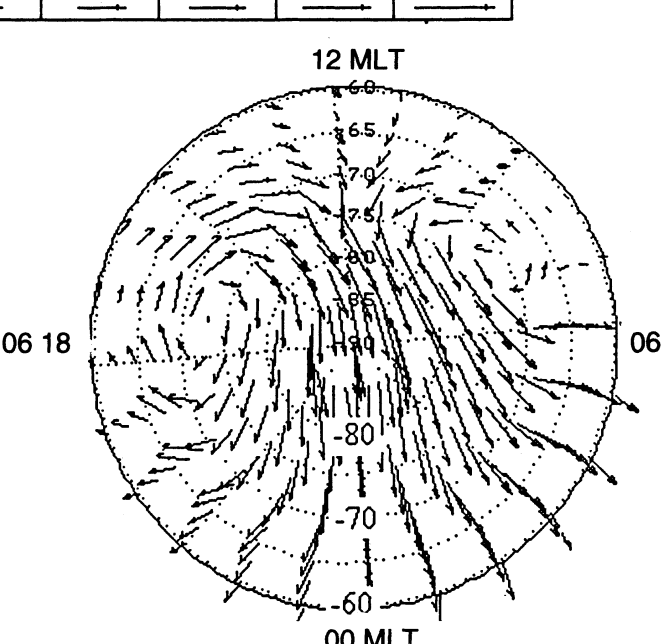

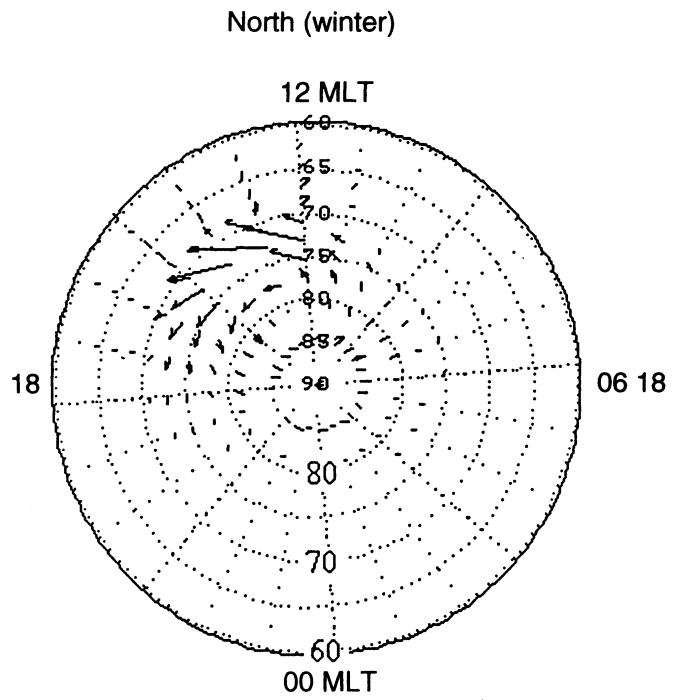

$00 \mathrm{MLT}$
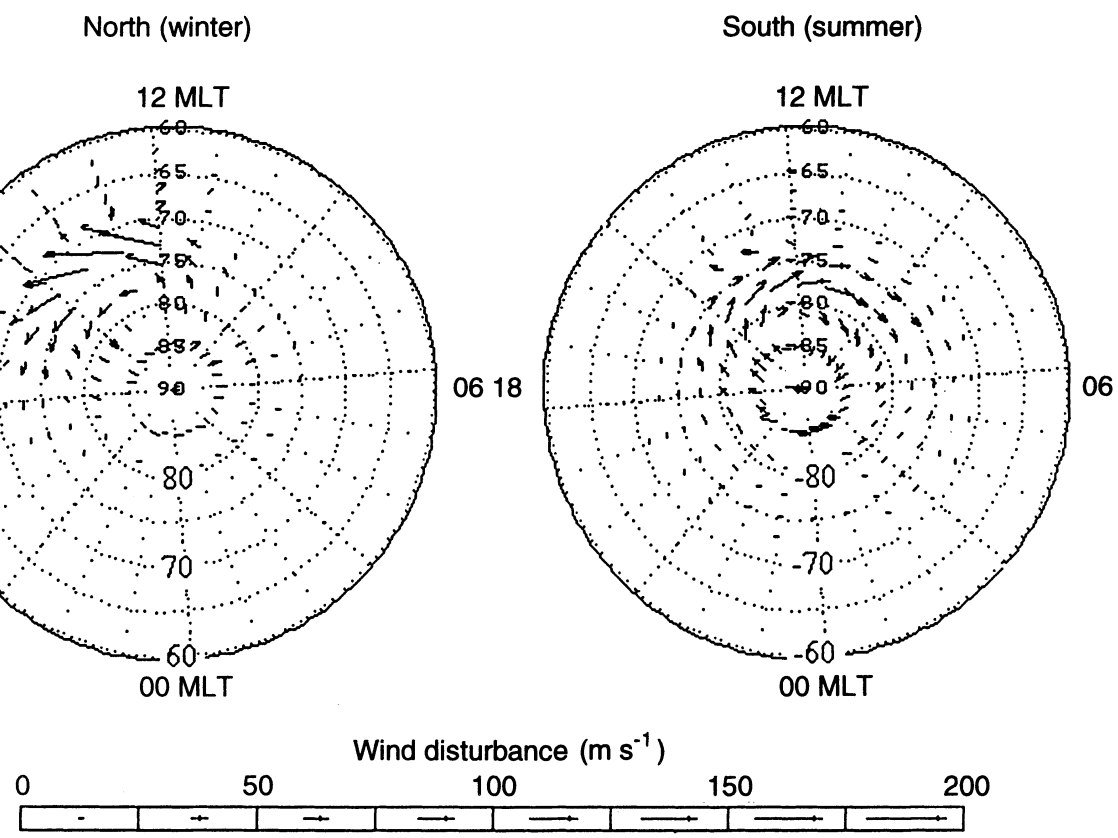

Fig. 8. The calculated patterns of the horizontal thermospheric wind velocity (top panel) and wind disturbance (bottom panel) at height $300 \mathrm{~km}$ at 0200 UT for 28 January, 1992 in the Northern (winter, left plots) and Southern (summer, right plots) Hemispheres (variant 2 of the calculations)

region in the Northern (winter) Hemisphere and the westward wind disturbance of about $100 \mathrm{~m} / \mathrm{s}$ in the cusp region in the Southern (summer) Hemisphere created by ion drag due to the FACs related to the IMF $B_{y}<0$. The wind disturbances are located more poleward in the summer hemisphere. These wind disturbances lead to the total horizontal wind patterns shown in the top panel in Fig. 8 with the oppositely directed zonal winds in the afternoon cusp region: eastward in the Northern (winter) and westward in the Southern (summer) Hemisphere.

Figure 9 shows the calculated disturbances of the electron number density, electron, ion and neutral temperature due to the FACs in the cusp region at height $300 \mathrm{~km}$ along the meridian of 1319 MLT at 0200 UT on 28 January, 1992 for the Northern (winter; solid lines) and Southern (summer; dashed lines) Hemispheres. We can see from this figure that the summer thermospheric and ionospheric temperatures and densities react very weakly on the FACs in the cusp region whereas in the winter hemisphere there are noticeable disturbances, especially in the ion temperature, due to Joule heating. The electron number density disturbance is small, being negative due to the enhanced ion loss rate caused by the enhanced ion temperature (Schunk et al., 1976). 
28.01.92 0200 UT $1319 \mathrm{MLT} \quad \mathrm{h}=300 \mathrm{~km}$

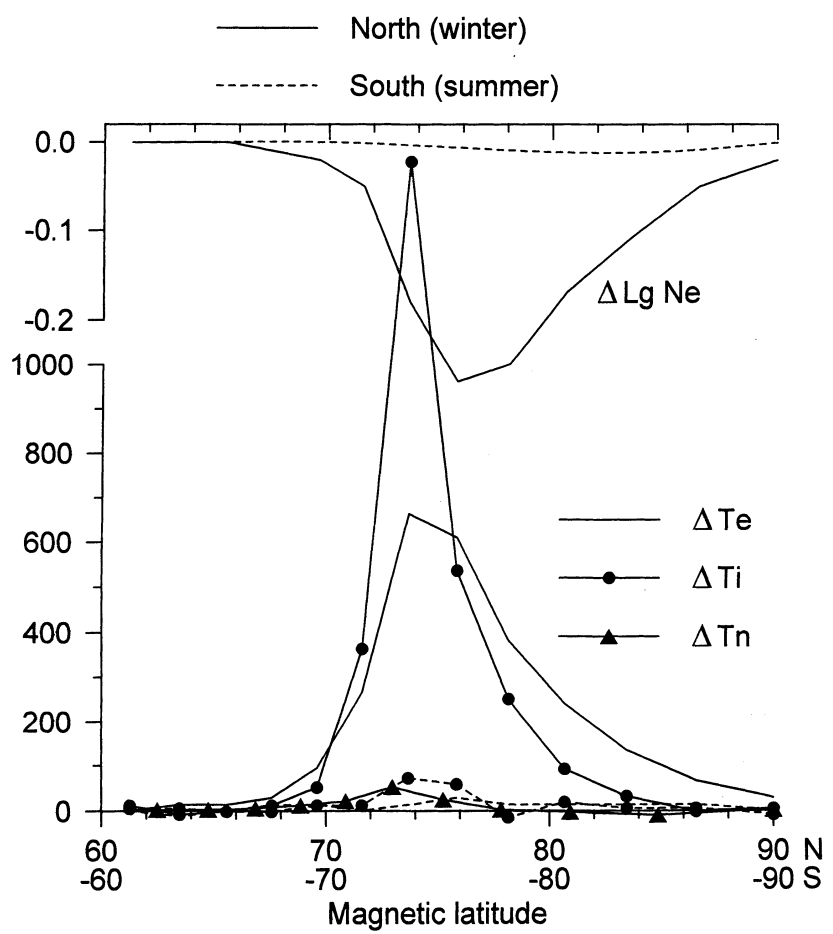

Fig. 9. The calculated disturbances of the electron number density, electron, ion and neutral temperature due to the FACs in the cusp region at height $300 \mathrm{~km}$ along the meridian of 1319 MLT at 0200 UT on 28 January, 1992 for the Northern (winter, solid lines) and Southern (summer, dashed lines) Hemispheres (variant 2 of the calculations)

\section{Discussion}

Now we can compare the results of the model calculations in the variant 1 and 2 between themselves and with the observations, and discuss the physical mechanisms of the seasonal effects in the response of the thermosphere and ionosphere to the FAC and precipitation variations in the cusp region.

\subsection{Comparison between the model results in the variants 1 and 2}

In variant 1 of the calculations, ionospheric convection is weak everywhere except in the confined cusp region where the winter electric fields are more than twice as large as summer ones (the maximum values are 70 and $30 \mathrm{mV} / \mathrm{m}$ ) due to the low ionospheric conductivities in the winter polar cap. In variant 2 of the calculations, ionospheric convection is stronger because of the larger input of FACs in the cusp and zone 1 regions. Again, electric fields are larger in the winter cusp region in comparison with the summer one (the maximum values are 100 and $50 \mathrm{mV} / \mathrm{m}$ ) despite FACs being larger in the summer hemisphere. This seasonal difference in the electric fields plays an important role in forming of the seasonal effects in the response of the thermospheric circulation, ion temperature and electron number density to the FACs in the cusp region.

When comparing the thermospheric wind disturbances calculated in variant 1 and 2 shown in Figs. 6 and 8 , we can see well that in variant 1 both zonal and meridional components of the wind velocity are of the same order of the magnitude (the eastward wind velocity disturbances are between -260 and $+160 \mathrm{~m} / \mathrm{s}$ and the northward ones are between -200 and $+360 \mathrm{~m} / \mathrm{s}$ ) both being larger in the winter hemisphere. However, in variant 2 of the calculations the zonal wind disturbance dominates having maximum values of about $200 \mathrm{~m} / \mathrm{s}$ in the winter hemisphere and $100 \mathrm{~m} / \mathrm{s}$ in the summer one. This difference between the variants has been caused by the difference in the thermospheric temperature disturbances which are significant in variant 1 due to the enhanced soft electron precipitation and insignificant in variant 2 (see Figs. 6, top panel and 9) when precipitation is the same as under the quiet conditions. Correspondingly, in variant 2 the wind disturbances are driven mainly by the ion drag whereas in variant 1 both ion drag and pressure gradient forcings have an important influence on the wind pattern. Neutral gas pressure gradient is larger in the winter cusp region (see top panel in Fig. 6) as well as electric fields so the total wind disturbances are larger in the winter hemisphere in both variants of the calculations.

Both ionospheric F2-region electron number density and electron temperature disturbances are positive due to the enhanced precipitation and significantly more intensive in variant 1 of the calculations in comparison with variant 2 (see Figs. 5, 9) where the electron concentration disturbances are negative due to the enhanced ion loss rate. The ion temperature disturbances, in contrast, are larger in variant 2 of the calculations in comparison with variant 1 due to the larger electric fields in variant 1 . They are larger in the winter cusp region again due to the larger electric fields in the winter polar cap in comparison with the summer one.

\subsection{Comparison with the observations}

The most extensive data set about the behavior of the thermosphere and ionosphere in the northern and southern polar caps has been obtained by the Dynamics Explorer satellites (Killeen and Roble, 1988). These data have been analyzed by many authors, including Rees et al. (1986) and Roble et al. (1987, 1988a) using their thermospheric general circulation models. A good general agreement has been found between TGCMpredicted neutral winds and DE-2 observations showing the dominant influence of magnetospheric convection on high-latitude circulation.

Figure 10 shows the geomagnetic polar plots of the mean thermospheric circulation measured on the DE-2 satellite (Thayer et al., 1987) between November and January in the years 1981-1982 in the Northern (left plot) and Southern (right plot) Hemispheres for the IMF $B_{y}<0$. A comparison of this figure with the top 


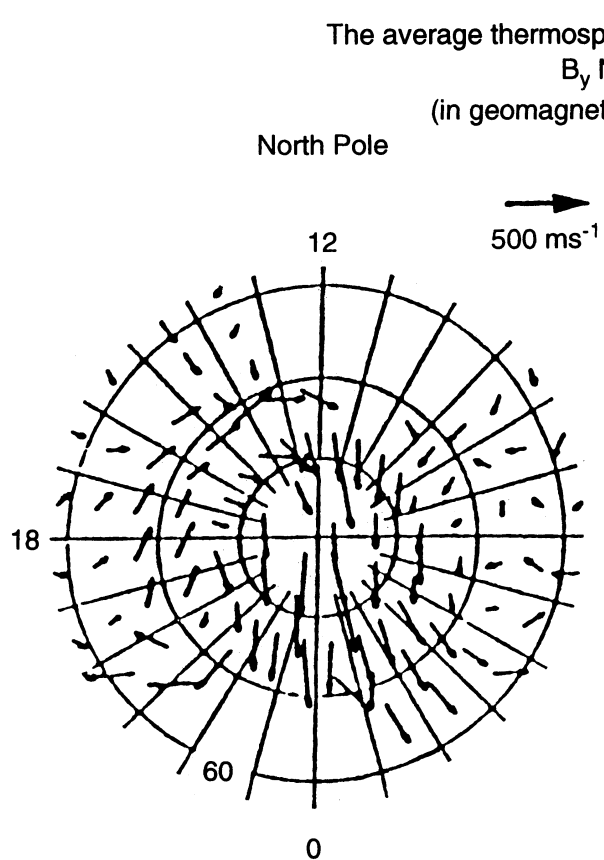

B NEG

heric neutral circulation

etic coordinates)

South Pole

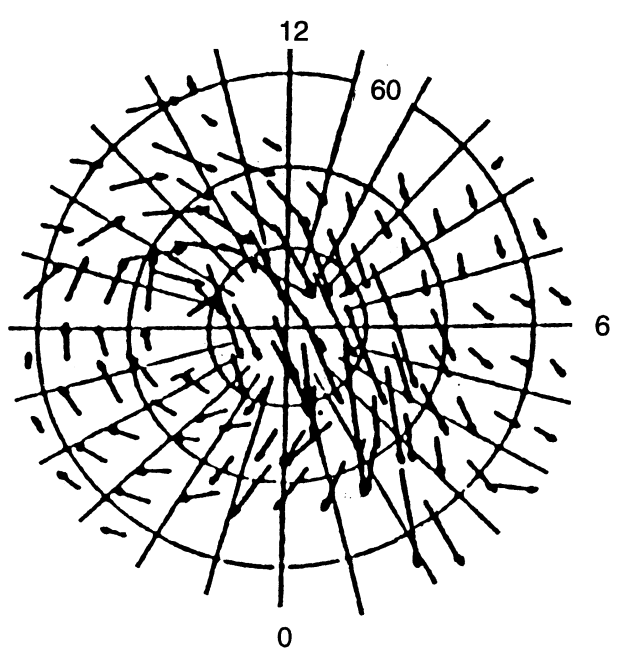

Fig. 10. The geomagnetic polar plots of the mean thermospheric circulation measured on the DE-2 satellite (Thayer et al., 1987) between November and January in the years 1981-1982 in the northern (left plot) and Southern (right plot) Hemispheres for the IMF $B_{y}<0$

panel in Fig. 8 shows that calculated patterns of the thermospheric circulation are in a good agreement with the average circulation for the Southern (summer) Hemisphere obtained from DE2 data but for the Northern (winter) Hemisphere there is some disagreement at high latitudes in the afternoon sector. The most distinctive feature of the calculated pattern in the northern cusp region is the eastward flow in the afternoon sector of the cusp region but it is absent in the average DE-2 data.

The DE-2 neutral wind vectors presented by Thayer et al. (1987) were averaged for two 3-month periods into bins of $5^{\circ}$ magnetic latitude and 1-h magnetic local time, whereas our calculations have been made for the specific event and UT moment and have a more high spatial resolution. To contribute to the average pattern significantly, there should be a sufficient number of events with IMF $B_{y}<0$ during one or more hours (to influence the winds via ion drag) when satellite orbits intersect (pass through) the afternoon sector of the cusp region. The eastward ion flow in the afternoon cusp region seen in the convection patterns for the Northern Hemisphere in Figs. 2 and 4 is not an unusual phenomenon. It is present in all empirical models of the ionospheric convection for IMF $B_{y}<0$ (e.g., Reiff and Burch (1985), Heppner and Maynard, 1987; Weimer, 1995) so it should have a corresponding reflection in the thermospheric circulation during the period with stable IMF $B_{y}<0$ as predicted by TGCMs (Rees et al., 1986) and as was observed by the Fabry-Perot interferometer at Longyearbyen, Spitsbergen $\left(78.2^{\circ} \mathrm{N}, 15.6^{\circ} \mathrm{E}\right.$, $75^{\circ}$ magnetic latitude) by McCormac and Smith (1984). They discovered that the zonal neutral winds averaged over 12 days near winter solstice between 1979 to 1983 when the IMF $B_{y}$ was negative were eastward in the afternoon sector of the cusp region.

It is interesting to compare our results with those obtained by $\mathrm{Wu}$ et al. (1996) which presented two detailed case studies of the ionospheric and thermospheric response to soft particle precipitation in the cusp/ cleft region using multi-instrument observations from the DE-2 satellite during orbits 688 and 748, together with supporting model calculations. They used a onedimensional hybrid satellite track model (Deng et al., 1995) to calculate thermospheric and ionospheric structures below the satellite's altitude employing various DE-2 measurements as inputs and upper boundary conditions. In both cases the IMF $B_{y}$ was negative for several hours and the zonal winds were eastward everywhere along the tracks in the polar cap (orbit 688 passed through the cusp region in the prenoon MLT sector and orbit 748 passed through the afternoon MLT sector). This is in contrast with the average pattern by Thayer et al. (1987) for IMF $B_{y}<0$ in the Northern Hemisphere (Fig. 10) but in agreement with the results by McCormac and Smith (1984) and with our results (Fig. 8). It is remarkable as well that their two cases reveal opposite behavior of the electron density in the cusp region. The electron density was enhanced during orbit 688 when the precipitation flux, $630 \mathrm{~nm}$ volume emission rate, electron and neutral temperature all were significantly enhanced, and the electron density was decreased in the cusp region during orbit 748 when the precipitation was weak, the $630 \mathrm{~nm}$ emission and electron temperature disturbances were relatively small, the neutral temperature was undisturbed and only ion temperature was distinctively increased in the cusp region. All these differences between the cases corres- 
pond quite well to the differences between our variants 1 and 2 of the model calculations.

\section{Summary and conclusions}

The seasonal effects in the thermosphere and ionosphere responses to the precipitating electron flux and fieldaligned current variations, of the order of $60 \mathrm{~min}$ in duration, in the summer and winter cusp regions have been investigated using the global numerical model of the Earth's upper atmosphere. Two variants of the calculations have been performed, both for the IMF $B_{y}<0$.

In the first variant, the model input data for the summer and winter precipitating fluxes and field-aligned currents have been taken as geomagnetically symmetric and equal to those used earlier in our calculations for the equinoctial conditions. The input soft electron distribution which is often observed poleward of $\mathrm{keV}$ ions is assumed to be somewhat distant from FAC, but we do not think that such an offset changes significantly the integrated ionospheric conductivity and, correspondingly, electric fields, because the ionization is produced by soft electron precipitation principally at high altitudes where the ion gyrofrequency exceeds the ion-neutral collision frequency (see, e.g., Roble and Rees, 1977). The soft electron precipitation has been increased ten times in comparison with background state in this variants as well as FACs in the cusp region, whereas the FACs in zone 1 have been weak. It has been found that both ionospheric and thermospheric disturbances are more intensive in the winter cusp region due to the lower conductivity of the winter polar cap ionosphere and correspondingly larger electric field variations leading to the larger Joule heating effects in the ion and neutral gas temperature, ion drag effects in the thermospheric winds and ion drift effects in the F2region electron concentration.

In the second variant, the calculations have been performed for the events of 28-29 January, 1992 when precipitations were weaker but the magnetospheric convection was stronger than in the first variant. Geomagnetically asymmetric input data for the summer and winter precipitating fluxes and field-aligned currents have been taken from the patterns derived by $\mathrm{Lu}$ et al. (1995) by combining data obtained from the satellite, radar and ground magnetometer observations for these events. Calculated patterns of the ionospheric convection and thermospheric circulation have been compared with observations and it has been established that calculated patterns of the ionospheric convection for both winter and summer hemispheres are in good agreement with the results by Lu et al. (1995). Calculated patterns of the thermospheric circulation are in good agreement with the average circulation for the Southern (summer) Hemisphere obtained from DE2 data for IMF $B_{y}<0$ (Thayer et al., 1987). However, for the Northern (winter) Hemisphere there is a disagreement at high latitudes in the afternoon sector of the cusp region. At the same time, the model results for this sector agree with the DE-2 data analyzed by $\mathrm{Wu}$ et al. (1996) and with the ground-based FPI data by McCormac and Smith (1984). This contradiction is a question to be tested by future observations in the cusp region such as EISCAT Svalbard Radar and optical measurements. All ionospheric and thermospheric disturbances in the second variant of the calculations are more intensive in the winter cusp region in comparison with the summer one and this seasonal difference is larger than in the first variant of the calculations, especially in the electron density and all temperature variations. This means that the seasonal effects in the cusp region are stronger in the thermospheric and ionospheric responses to the $\mathrm{FAC}$ variations than to the precipitation disturbances.

Acknowledgements. The authors would like to thank O. V. Martynenko for his assistance in performing the calculations. The Editor in chief thanks two referees for their help in evaluating the paper.

\section{References}

Beaujardiere O. de la., J. Watermann, P. Newell, and F. Rich, Relationship between Birkeland current regions, particle precipitation, and electric fields, J. Geophys. Res., 98, 7711-7720, 1993.

Bythrow, P. F., T. A. Potemra, and R. A. Hoffman, Observations of field-aligned currents, particles and plasma drift in the polar cusps near solstice, J. Geophys. Res., 87, (A7), 5131-5139, 1982.

Deng W., T. L. Killeen, A. G. Burns, R. W. Johnson, B. A. Emery, R. G. Roble, J. D. Winningham, and J. B. Cary, Onedimensional hybrid satellite track model for the Dynamics Explorer 2 (DE 2) satellite, J. Geophys. Res., 100, 1611-1624, 1995.

Erlandson, R. E., L. J. Zanetti, T. A. Potemra, and P. F. Bythrow, IMF $B_{y}$ dependence of region 1 Birkeland currents near noon. J. Geophys. Res., 93, 9804-9814, 1988.

Friis-Christensen, E., Y. Kamide, A. D. Richmond, and S. Matsushita, Interplanetary magnetic field control of high-latitude electric fields and currents determined from Greenland magnetometer data, J. Geophys. Res., 90, 1325-1338, 1985.

Fujii, R., and T. Iijima, Control of the ionospheric conductivities on large-scale Birkeland current intensities under geomagnetic quiet conditions, J. Geophys. Res., 92, 4505-4513, 1987.

Fuller-Rowell, T. J., D. Rees, S. Quegan, R. J. Moffett, and G. J. Bailey, Simulations of the seasonal and universal time variations of the high-latitude thermosphere and ionosphere using a coupled, three-dimensional model. Pure Appl. Geophys. 127, 189-217, 1988.

Garbe, G. P., J. S. Murphree, L. L. Cogger, and J. Woch, Cusp/ cleft region as observed by the Viking UV imager, J. Geophys. Res. 98, 6059-6068, 1993.

Gussenhoven, M. S., Low-altitude convection, precipitation, and current patterns in the baseline magnetosphere, Rev. Geophys., 26, 792-802, 1988.

Heppner, J. P., and N. C. Maynard, Empirical high-latitude electric field models. J. Geophys. Res., 92, 4467-4489, 1987.

Iijima, T., and T. A. Potemra, Field-aligned currents in the dayside cusp observed by Triad, J. Geophys. Res., 81, 5971-5979, 1976.

Kelly, J. D., and J. F. Vickrey, F-region ionospheric structure associated with antisunward flow near the dayside polar cusp, Geophys. Res. Lett., 1, 907-910, 1984.

Killeen, T. L., and R. G. Roble, Thermosphere dynamics: contributions from the first 5 years of the Dynamics Explorer Program. Rev. Geophys., 26, 329-367, 1988. 
Kirkwood, S., Lower thermosphere mean temperatures, densities, and winds measured by EISCAT: seasonal and solar cycle effects, J. Geophys. Res., 101, 5133-5148, 1996.

Kofman W., and V. B. Wickwar, Very high electron temperatures in the daytime F-region at Sondrestrom, Geophys. Res. Lett., 1, 919-922, 1984.

Lu, G., A. D. Richmond, B. A. Emery, P. H. Reiff, O. de la Beaujardire, F. J. Rich, W. F. Denig, H. W. Kroehl, L. R. Lyons, J. M. Ruohoniemi, E. Friis-Christensen, H. Opgenoorth, M. A. L. Persson, R. P. Lepping, A. S. Rodger, T. Hughes, A. McEwin, S. Dennis, R. Morris, G. Burns, and L. Tomlinson, Interhemispheric asymmetry of the high-latitude ionospheric convection pattern, J. Geophys. Res., 99, 6491-6510, 1994

Lu, G., L. R. Lyons, P. H. Reiff, W. F. Denig, O. de la Beaujardiere, H. W. Kroehl, P. T. Newell, F. J. Rich, H. Opgenoorth, M. A. L. Persson, J. M. Ruohoniemi, E. FrissChristensen, L. Tomlinson, R. Morris, G. Burns, and A. McEwin, Characteristics of ionospheric convection and field-aligned current in the dayside cusp region, J. Geophys. Res., 100, $11845-11861,1995$.

McCormac, F. C., and R. W. Smith, The influence of the interplanetary magnetic field $\mathrm{Y}$ component on ion and neutral motions in the polar thermosphere, Geophys. Res. Lett., 11, 935-938, 1984.

McDiarmid, I. B., J. R. Burrows, and M.D. Wilson, Large-scale magnetic field perturbations and particle measurements at $1400 \mathrm{~km}$ on the dayside, J. Geophys. Res., 84, 1431-1441, 1979.

Namgaladze, A. A., Y. N. Korenkov, V. V. Klimenko, I. V. Karpov, F. S. Bessarab, V. A. Surotkin, T. A. Glushchenko, and N. M. Naumova, Global model of the thermosphere-ionosphere-protonosphere system, Pure Appl. Geophys., A. A., 127, 219-254, 1988.

Namgaladze, A. A., Y. N. Korenkov, V. V. Klimenko, I. V. Karpov, F. S. Bessarab, V. A. Surotkin, T. A. Glushchenko, and N. M. Naumova, Global numerical model of the thermosphere, ionosphere, and protonosphere of the Earth, Geomagn. Aeron., 30, 612-619, 1990.

Namgaladze, A. A., Y. N. Korenkov, V. V. Klimenko, I. V. Karpov, V. A. Surotkin, and N. M. Naumova, Numerical modelling of the thermosphere-ionosphere-protonosphere system, J. Atmos. Terr. Phys., 53, 1113-124, 1991.

Namgaladze, A. A., Y. N. Korenkov, V. V. Klimenko, I. V. Karpov, V. A. Surotkin, F. S. Bessarab, and V. M. Smertin, Numerical modelling of the global coupling processes in the near-Earth space environment, COSPAR Coll. Ser., 5, 807-811, 1994.

Namgaladze, A. A., O. V. Martynenko, and A. N. Namgaladze, Global model of the upper atmosphere with variable latitudinal steps of numerical integration, IUGG XXI General Assembly, Boulder, 1995, Abstracts. GAB41F-6, B150, 1995, and Geomagn. Aeron., 36, 89-95, 1996a (in Russian).

Namgaladze, A. A., A. N. Namgaladze, M. A. Volkov, Numerical modelling of the thermospheric and ionospheric effects of magnetospheric processes in the cusp region, Ann. Geophys., 14, 1343-1355, 1996b.

Newell, P. T., and C.-I. Meng, Hemispherical asymmetry in cusp precipitation near solstices, J. Geophys. Res., 93, 2643-2648, 1988.

Ohtani, S., T. A. Potemra, P. T. Newell, L. J. Zanetti, T. Iijima, M. Watanabe, L. G. Blomberg, R. D. Elphinstone, J. S. Murphree, M. Yamauchi, and J. G. Woch, Four large-scale field-aligned current systems in the dayside high-latitude region, J. Geophys. Res., 100, 137-153, 1995.

Oliver, W. L., J. C. Foster, J. M. Holt, G. B. Loriot, V. B. Wickwar, J. D. Kelly, O. de la Beaujardiere, P. F. Bythrow, C.-I. Meng, F. J. Rich, and R. E. Huffman, Initial Millstone Hill, Sondrestrom, and HILAT observations of thermospheric temperatures and frictional heating, Geophys. Res. Lett., 1, 911914, 1984.

Rees, D., T. J. Fuller-Rowell, R. Gordon, J. P. Heppner, N. C. Maynard, N. W. Spencer, L. E. Wharton, P. B. Hays, and T. L.
Killeen, A theoretical and empirical study of the response of the high-latitude thermosphere to the sense of the "Y" component of the interplanetary magnetic field, Plant. Space Sci., 34, 1-40, 1986.

Reiff, P. H., and J. L. Burch, IMF $B y$-dependent plasma flow and Birkeland currents in the dayside magnetosphere. 2. A global model for northward and southward IMF. J. Geophys. Res., 90, 1595-1609, 1985.

Richmond, A. D., and Y. Kamide, Mapping electrodynamical features of the high-latitude ionosphere from localized observations, technique, J. Geophys. Res., 93, 5741-5759, 1988.

Richmond, A. D., E. C. Ridley, and R. G. Roble, A thermosphereionosphere general circulation model with coupled electrodynamics. Geophys. Res. Lett., 19, 601-604, 1992.

Robinson, R. M., D. S. Evans, T. A. Potemra, and J. D. Kelly, Radar and satellite measurements of an F-region ionization enhancement in the post-noon sector, Geophys. Res. Lett., 1, 899-902, 1984.

Roble, R. G., and M. H. Ress, Time-dependent studies of the aurora: effects of particle precipitation on the dynamic morphology of ionospheric and atmospheric properties, Planet. Space. Sci., 25, 991-1010, 1977.

Roble, R. G., J. M. Forbes, and F. A. Marcos, Thermospheric dynamics during the March 22, 1979, magnetic storm, 1, model simulations, J. Geophys. Res., 92 (6), 6045-6068, 1987.

Roble, R. G., T. L. Killeen, N. W. Spencer, R. A. Heelis, P. H. Reiff, and J. D. Winningham, Thermospheric dynamics during November 21-22, 1981: Dynamics Explorer measurements and thermospheric general circulation model predictions, J. Geophys. Res., 93, 209-225, 1988a.

Roble, R. G., E. C. Ridley, A. D. Richmond, and R. E. Dickinson, A coupled thermosphere/ionosphere general circulation model. Geophys. Res. Lett., 15, 1325-1328, 1988b.

Roble, R. G., and E. C. Ridley, A thermosphere-ionospheremesosphere-electrodynamics general circulation model (TIMEGCM): equinox solar cycle minimum conditions $(30-500 \mathrm{~km})$, Geophys. Res. Lett., 21, 417-420, 1994.

Sandholt, P. E., C. J. Farrugia, L. F. Burlaga, J. A. Holtet, J. Moen, B. Lybekk, B. Jacobsen, D. Opsvik, A. Egeland, R. Lepping, A. J. Lazarus, T. Hansen, A. Brekke, E. FriisChristensen, Cusp/cleft auroral activity in relation to solar wind dynamic pressure, interplanetary magnetic field $B_{z}$ and $B_{y}$. J. Geophys. Res., 99, 17,323-17,342, 1994.

Shepherd, G. S., Dayside cleft aurora and its ionospheric effects. Rev. Geophys. Space Phys., 17 (8), 2017-2033, 1979.

Schunk, R. W., A mathematical model of the middle and high latitude ionosphere, Pure Appl. Geophys., 127, 255-303, 1988.

Schunk, R. W., P. M. Banks, and W. J. Raitt, Effects of electric fields and other processes upon the night-time high-latitude Flayer, J. Geophys. Res., 81, 3271-3282, 1976.

Smith, R. W., Interferometer observations of ion and neutral dynamics, in The Polar Cusp, Ed. J. H. Holtet, and A. Egeland, pp. 243-260, D. Reidel, Norwell, Mass., 1984.

Sojka, J. J., Global scale physical models of the F-region ionosphere, Rev. Geophys., 27, 371-403, 1989.

Sojka, J. J., and R. W. Schunk, Theoretical study of the seasonal behavior of the global ionosphere at solar maximum, J. Geophys. Res., 94, (A6), 6739-6749, 1989.

Taguchi, S., M. Sugiura, J. D. Winningham, J. A. Slavin, Characterization of the IMF $\mathrm{B}_{\mathrm{y}}$-dependent field-aligned currents in the cleft region based on DE-2 observations. J. Geophys. Res., 98, 1393-1407, 1993.

Thayer, J. P., T. L. Killeen, F. G. McCormac, C. R. Tschan, J.-J. Ponthieu, N. W. Spencer, Thermospheric neutral wind signatures dependent on the east-west component of the interplanetary magnetic field for Northern and Southern Hemispheres as measured from Dynamics Explorer-2, Ann. Gephysicae, 5A, 363-368, 1987.

Vennerstrom, S., E. Friis-Christensen, T. S. Jorgensen, O. Rasmussen, C. R. Clauer, and V. B. Wickwar, Ionospheric currents and 
F-region plasma boundaries near the dayside cusp, Geophys. Res. Lett., 1, 903-906, 1984.

Weimer, D. R., Models of high-latitude electric potentials derived with a least error fit of spherical harmonic coefficients, $J$. Geophys. Res., 100, 19 595-19 607, 1995.

Wickwar, V. B., Thermospheric neutral wind at $-39^{\circ}$ azimuth during the daytime sector at Sondrestrom, Geopohys. Res. Lett., 1, 927-930, 1984.

Woch, J., M. Yamauchi, R. Lundin, T. A. Potemra, and L. J. Zanetti, The low-latitude boundary layer at mid-altitudes: relation to large-scale Birkeland currents, Geophys. Res. Lett., 10, 2251-2254, 1993.

Wu, Q., T. L. Killeen, W. Deng, A. G. Burns, J. D. Winningham, N. W. Spencer, R. A. Heelis, and W. B. Hanson, Dynamics
Explorer 2 satellite observations and satellite track model calculations in the cusp/cleft region, J. Geophys. Res., 101, 5329-5342, 1996.

Xu, D., and M. G. Kivelson, Polar cap field-aligned currents for southward interplanetary magnetic fields, J. Geophys. Res., 99, 6067-6078, 1994.

Yamauchi, M., and T. Araki, The interplanetary magnetic field $B_{y^{-}}$ dependent field-aligned current in the dayside polar cap under quiet conditions, J. Geophys. Res., 94, 2684-2690, 1989.

Yamauchi, M., R. Lundin, and J. Woch, The interplanetary magnetic field $B_{y}$, effects on large scale field-aligned currents near local noon: contributions from cusp part and non-cusp part, J. Geophys. Res., 98, 5761-5767, 1993. 